DOI: 10.20472/IAC.2019.045.017

TABANDEH HARRAF

University of Northern Colorado, United States

\title{
EFFECTS OF FOUR VARIED TEACHING PEDAGOGIES ON FRESHMEN STUDENT SUCCESS
}

\begin{abstract}
:
Teaching the new generation of the students is becoming increasingly challenging, regardless of the course content and rigor. Instructors are constantly looking for creative methodologies to achieve the course objectives while accommodating different learning styles. New college-bound students come with various technical competencies and expectations about what college experience and teaching pedagogy should entail. Some are independent thinkers while others require intentional instructional pedagogy to be successful. While there is no one perfect way, teachers across the globe strive to identify a right mix of pedagogies to effectively capitalize on the learning capacity and styles of the new generation of college students and the best way of preparing them for the fast paced and ever changing knowledge economy. This presentation will compare four different methodologies employed to teach a freshman introductory computer literacy course. The four methods are traditional lecture, online, hybrid, flipped classroom.

While each method has its own merits, assorted cohort of students respond differently to the subject matter resulting in varied student learning experiences. Creating a right mix of teaching pedagogies to strike a right balance in identifying appropriate methodology has presented many educators with a challenge. Since every class is comprised of students with numerous learning styles, identifying such a mix of pedagogies becomes a practice of trial and error.

This study has examined the success of each methodology, using the end of the course grade as a proxy, to determine whether there is one clear methodology that reveals significant correlation between the teaching methodology and overall student success. This analysis, while in its early stages is envisioned to assist in prescribing a mix of teaching pedagogies that could be employed for teaching the freshmen computer literacy course.

An extension of this study is to correlate a number of variables to identify the influence of other underlying sources on the success of students under a certain teaching pedagogy. Variables such as high school GPA, ACT/SAT score, College GPA, and class standing could reveal additional insight on prescribing a tailored teaching methodology that underwrites student success and retention of the course content.
\end{abstract}

\section{Keywords:}

Teaching Pedagogy, Student Success, Learning Styles 